\title{
Adolescent clinical outcomes for young people with attention-deficit hyperactivity disorder
}

Kate Langley, Tom Fowler, Tamsin Ford, Ajay K. Thapar, Marianne van den Bree, Gordon Harold, Michael J. Owen, Michael C. O'Donovan and Anita Thapar

\section{Background}

Attention-deficit hyperactivity disorder (ADHD) is recognised as a common, disabling condition. Little information is available regarding the long-term outcomes for individuals with ADHD in the UK.

\section{Aims}

To examine the 5-year outcome for a UK cohort of children with diagnosed, treated ADHD and identify whether maternal and social factors predict key outcomes.

\section{Method}

One hundred and twenty-six school-aged children (mean age 9.4 years, s.d. $=1.7$ ) diagnosed with ADHD were reassessed 5 years later during adolescence (mean age 14.5 years,

s.d. =1.7) for ADHD, conduct disorder and other antisocial behaviours.

\section{Results}

Most adolescents (69.8\%) continued to meet full criteria for $A D H D$, were known to specialist services and exhibited high levels of antisocial behaviour, criminal activity and substance use problems. Maternal childhood conduct disorder predicted offspring ADHD continuity; maternal childhood conduct disorder, lower child IQ and social class predicted offspring conduct disorder symptoms.

\section{Conclusions}

The treatment and monitoring of ADHD need to be intensified as outcomes are poor especially in offspring of mothers with childhood conduct disorder symptoms.

\section{Declaration of interest}

None.
Attention-deficit hyperactivity disorder (ADHD) is the most common reason for follow-up in UK child and adolescent mental health services (CAMHS). ${ }^{1}$ Recognition and treatment are considered important. ${ }^{2}$ However, little is known regarding longterm outcomes of children receiving ADHD interventions in UK CAMHS. The clinical outcomes of ADHD in other countries are poor and the MTA trial ${ }^{3}$ found treatment benefits reduced over time. Utilising a sample of UK individuals diagnosed with ADHD in childhood reassessed in adolescence, we investigated the prevalence of key adolescent outcomes examining whether maternal and social factors influence the course of ADHD.

\section{Method}

\section{Sample}

The Cardiff Longitudinal ADHD Sample Study (CLASS) recruited children between 1998 and 2002 from child and adolescent psychiatry and paediatric out-patient clinics across north-west and south-west England and South Wales, UK. ${ }^{4}$ Initially, 98\% of clinic families agreed to participate. Five years later, we invited individuals who had reached adolescence (aged over 12 years) to participate in a follow-up study. Those eligible for follow-up were 157 British White children, aged 6-13 years (mean age 9.4 years, s.d.=1.7), who met diagnostic criteria for DSM-IV $\mathrm{ADHD}$ at baseline (time $1\left(T_{1}\right)$ ) and were currently (time $2\left(T_{2}\right)$ ) aged over 12 years. These children were newly referred at $T_{1}$, had IQ test scores above 70, no diagnosis of autism or related disorders, Tourette syndrome or any neurological conditions. At initial assessment, all clinicians responsible for the care of the children were provided with a written feedback summary of the research diagnostic assessment information confirming the ADHD diagnosis and any comorbid conditions such as conduct disorder.

At follow-up, participants were aged 12-18 years (mean age 14.5 years, s.d. $=1.7)$. Contact had been maintained with families and $95 \%$ of the original sample was traced; $80 \% \quad(n=126)$ participated in the follow-up. We obtained informed consent and assent from parents and children at both time points. The North-West England Multi-Centre Research Ethics Committee, UK, approved the study.

Comparison data, using identical questionnaire measures, on substance use were available for 121 age- and gender-matched controls ( 7 females, 114 males; mean age 14.5 years, s.d. $=1.5$ ) from a general population-based sample, the Cardiff Study of All Wales and North West of England Twins (CaStANET) ${ }^{6}$ from the same geographical location as CLASS. Only one twin from a pair was included. Comparison data were obtained concurrently to CLASS $T_{2}$ assessments. The CaStANET prevalence rates for adolescent cigarette smoking and alcohol use were comparable with other UK studies, and equal prevalence of questionnaireassessed ADHD and conduct disorder behaviours were observed. ${ }^{7,8}$

\section{Clinical assessments and outcome measures}

ADHD

At baseline and follow-up, the parent version of the Child and Adolescent Psychiatric Assessment (CAPA), ${ }^{9}$ a semi-structured research diagnostic interview, was used to assess DSM-IV and ICD-10 $0^{10}$ ADHD symptoms. The Child ADHD Teacher Telephone Interview (ChATTI) ${ }^{11}$ was used to assess symptoms and impairment at school. Teacher reports were unavailable for those who had left school at $T_{2}$. To avoid excluding data from older individuals, in these cases parental report of impairment in school or community settings was used to assess symptom pervasiveness. Interviews were conducted by trained, supervised psychology graduates and child psychiatrists, and perfect interrater diagnostic reliability was found; $\kappa=1.00$ for DSM-IV ADHD and ICD-10 hyperkinetic disorder. Because all individuals had baseline ADHD diagnoses and we were interested in predicting the change in these symptoms over time, we calculated an ADHD symptom change score (DSM-IV total ADHD symptom score at 
$T_{2}$ minus ADHD total symptom score at $T_{1}$ ). For ease of interpretation, this score was transformed to reverse the outcome (so a greater decrease in ADHD symptoms - more change resulted in a higher score).

\section{Antisocial behaviour}

The CAPA-parent version ${ }^{9}$ was used at both time points to assess clinical symptoms of antisocial behaviours characterising DSM-IV oppositional defiant disorder and conduct disorder.

At follow-up, adolescents were also interviewed using the CAPA-child version. ${ }^{12}$ Adolescent antisocial symptoms were considered present if reported by either the parent or adolescent within the past 12 months. ${ }^{13}$ For our adolescent conduct disorder outcome measure, we investigated $T_{2}$ total conduct disorder scores. Where significant association was observed between adolescent conduct disorder scores and our putative predictor variables, we controlled for baseline conduct disorder symptoms. At $T_{1}, 18$ individuals (14.5\%) met diagnostic criteria for conduct disorder.

\section{Impairment of functioning}

The effect of symptoms on family, school or peer relations was assessed using the CAPA. ${ }^{9,12}$ Impairment was assessed for each type of disorder described by interviewees as interfering 'never', 'rarely', 'sometimes' or 'often'. Ratings of 'sometimes' and 'often' were taken as indicating significant impairment.

\section{Adolescent substance use}

Adolescent lifetime and current use of alcohol, cigarettes and cannabis was assessed using self-reported questionnaire measures from the 'Add Health' study. ${ }^{14}$

\section{Other measures}

Child and parent CAPA interviews provided information on police contact resulting from the child's behaviour (as opposed to being the victim of, or reporting, a crime) as lifetime ever and during the previous 3 months (endorsed if reported by either informant). Full-scale IQ scores were obtained at $T_{1}$ using the Wechsler Intelligence Scale for Children (WISC-III) assessment. ${ }^{15}$ The mean full-scale IQ score was 91.8 (s.d.=12.6).

Data on social class were obtained at $T_{1}$ using standard parental occupation measures. ${ }^{16}$ Families were split into those from high (classes 1 and 2), $n=32,26.7 \%$; medium (classes 3 skilled and non-skilled, and class 4 ), $n=42,35.0 \%$; and low social class (class 5 and unemployed or unclassified individuals), $n=46$, $38.3 \%$. Two individuals had missing data and four stated the armed forces as their occupation and, due to difficulties in classification, were not included in these analyses. Parents also reported on their children's birth weight and friendships. Responses could be classed as 'being normal' (21.7\%), 'having some friends with some problems with friendships' $(63.5 \%)$ or 'having no friends' (14.8\%).

Finally, mothers reported on their own childhood ADHD symptoms aged 7-12 years using the Barkley Adult ADHD scale ${ }^{17}$ and on their childhood conduct disorder symptoms (before age 18 years) using a presence/absence checklist of DSM-IV conduct disorder symptoms. Over half the sample had missing data on unavailable fathers, thus father symptoms were not examined.

\section{Medication and service use}

Service use related to mental health and medication was measured using the Children's Service Interview with the parent, asking about service use within the past year. ${ }^{18}$ No information regarding medication adherence was obtained.

\section{Statistical analysis}

Chi-squared and $t$-test analyses were used to compare $T_{1}$ characteristics between those who did and did not participate at $T_{2}$ and to compare prevalence of substance use between the CLASS and CaStANET samples. Linear regression was used to investigate predictors of outcome. All analyses were performed using SPSS (Version 12) for Windows. The predictors investigated reflected maternal factors (childhood ADHD and conduct disorder symptoms) and social factors (friendships and social class) previously implicated as potentially important. ${ }^{19}$ We additionally examined child IQ and birth weight, found to predict favourable outcomes in the largest treatment trial of ADHD (the MTA trial) ${ }^{20}$ as well as child gender. Finally, we adjusted for age and prescribed medication.

\section{Results}

Participation rates at follow-up were $80.3 \%$. No significant baseline differences were found between those who did and did not participate (Table 1). Some $T_{2}$ items were not completed by interviewees. Data on ADHD symptoms, diagnoses and impairment were available for 126 individuals, antisocial behaviour for 124 individuals and substance use for 117. There were no baseline differences between those with complete and incomplete $T_{2}$ data, apart from an older age at time of assessment in those without teacher information (data available from author on request).

\section{ADHD continuity and associated impairment}

The mean ADHD symptom change score was 2.91 (s.d.=3.54) indicating symptom reduction over time. At $T_{2}$, the majority of adolescents $(n=88,69.8 \%)$ continued to meet DSM-IV ADHD diagnostic criteria (combined, inattentive and hyperactive-impulsive subtypes) and ICD-10 criteria for hyperkinetic disorder ( $n=63$, $51 \%)$. A total of 70 individuals $(68.9 \%)$ had the same DSM-IV subtype diagnosis as at $T_{1}$. Even among those not meeting full diagnostic criteria $(n=33)$, the majority $(n=20)$ still reported significant impairment from their remaining ADHD symptoms. Twelve $(10 \%)$ of the sample showed insufficient symptoms and impairment for an ADHD diagnosis. All of these individuals had been prescribed stimulant medication at some point and four continued to take it at follow-up. The remaining eight $(6 \%$ of whole sample) seem to have recovered both symptomatically and functionally. Finally, one individual reported symptoms that would meet diagnostic criteria, but without any impairment. Attention-deficit hyperactivity disorder symptom score change was not associated with the time between assessments $(\beta=0.07$, $t=0.81, P=0.42$ ), suggesting symptom change is not just because of the length of time since diagnosis.

\section{Antisocial outcomes}

\section{Conduct disorder and associated impairment}

At $T_{2}, 39$ individuals $(31.5 \%)$ met DSM-IV conduct disorder diagnostic criteria, a significant increase in those diagnosed at $T_{1}\left(\chi^{2}=15.94, P<0.001\right)$. A total of $27(21.8 \%)$ individuals developed conduct disorder between $T_{1}$ and $T_{2}$ (emergent conduct disorder) with $12(66.7 \%)$ showing conduct disorder persisting between time points. This showed high continuity of conduct disorder diagnosis, although conduct disorder did desist for $6(33.3 \%)$ individuals. A total of $79(63.7 \%)$ individuals 


\begin{tabular}{|c|c|c|c|c|}
\hline & \multirow{2}{*}{$\begin{array}{l}\text { Participants } \\
\qquad(n=126)\end{array}$} & \multirow{2}{*}{$\begin{array}{l}\text { Non-participants } \\
\qquad(n=31)\end{array}$} & \multicolumn{2}{|c|}{ Participant/non-participant comparisons } \\
\hline & & & Test statistic & $P$ \\
\hline \multicolumn{5}{|l|}{$T_{1}$ data } \\
\hline Male, $n(\%)$ & $118(94)$ & $28(87.5)$ & $\chi^{2}=0.12($ d.f. $=1)$ & 0.73 \\
\hline Socioeconomic status, low: $n$ (\%) & $46(38)$ & $10(32)$ & $\chi^{2}=0.12($ d.f. $=2)$ & 0.94 \\
\hline Conduct disorder diagnosis, $n$ (\%) & $18(14.5)$ & $4(12.5)$ & $\chi^{2}=0.20($ d.f. $=1)$ & 0.66 \\
\hline Oppositional defiant disorder diagnosis, $n$ (\%) & $61(48.4)$ & $19(61.3)$ & $\chi^{2}=1.41(\mathrm{~d} . \mathrm{f}=1)$ & 0.24 \\
\hline ADHD symptoms, mean (s.d.) & $14.56(2.35)$ & $14.77(2.69)$ & $t=0.39$ & 0.70 \\
\hline \multicolumn{5}{|l|}{$T_{2}$ data } \\
\hline Age, years: mean (s.d.) & $14.7(1.7)$ & - & - & - \\
\hline ADHD symptoms, mean (s.d.) & $12.07(4.94)$ & - & - & - \\
\hline Conduct disorder symptoms, mean (s.d.) & $1.99(1.87)$ & - & - & - \\
\hline \multicolumn{5}{|l|}{ Stimulant medication, $n(\%)$} \\
\hline Ever & 117 (93) & - & - & - \\
\hline Current & $83(66)$ & - & - & - \\
\hline Currently in contact with CAMHS, $n(\%)$ & $88(70)$ & - & - & - \\
\hline
\end{tabular}

showed no diagnosis of conduct disorder at either time point. The majority of individuals $(62 / 85,72.9 \%)$ not reaching the diagnostic threshold for conduct disorder at $T_{2}$ reported impairment due to conduct disorder symptoms. For those with a $T_{2}$ conduct disorder diagnosis, 31 (79.5\%) met diagnostic criteria for childhood-onset conduct disorder, presenting with one or more symptoms before age 10 years. The mean number of conduct disorder symptoms at $T_{2}$ was $1.99($ s.d. $=1.87)$.

\section{Specific antisocial behaviours}

A substantial minority of individuals at follow-up engaged in serious antisocial acts, including using a weapon $(15 / 124,12 \%)$, committing a crime involving confronting the victim (9/124, $7 \%)$, breaking and entering $(14 / 124,11 \%)$, stealing $(25 / 124$, $20 \%)$, fire-setting $(16 / 124,13 \%)$ and vandalism $(27 / 124,22 \%)$, with $47 \%(59 / 124)$ reporting at least one of these behaviours. Over half reported at least one police contact $(75 / 124,61 \%)$ with first police contact prior to adolescence (mean age 10 years, s.d. $=2.6$ ). Police contact in the past 3 months was reported by $33 / 124(27 \%)$.

\section{Adolescent alcohol, cigarette and cannabis use}

The rates of substance use and comparisons with the CaStANET sample are provided in Table 2. The ADHD sample were more likely to report heavier and more hazardous use of alcohol, more recent (within previous 30 days) use of cannabis and regular recent use of cigarettes. They were also significantly younger when they first tried cigarettes $(11.0 v .12 .7$ years, $t=-3.2, P=0.002)$ and cannabis (12.6 v. 13.8 years, $t=-2.4, P=0.018)$ but not alcohol (12.7 years $v .12 .9, t=-1.1, P=0.3)$. There was no association between any measure of substance use and baseline ADHD $(P>0.1)$ or conduct disorder severity $(P>0.07)$, with the exception of heavy recent use of cigarettes, which was more likely in individuals with greater baseline conduct disorder severity (odds ratio $(\mathrm{OR})=1.42,95 \%$ CI 1.01-1.99, $P=0.046$ ). Cannabis and cigarette use were associated with greater concurrent conduct disorder severity $(P<0.018)$.

\section{Predictors of ADHD and antisocial behaviour at follow-up}

At $T_{2}, 63 \%$ of the sample reported being currently prescribed stimulant medication. Those prescribed stimulant medication had significantly more ADHD symptoms and rates of ADHD diagnosis than those no longer using medication. ${ }^{21}$ Medication use was not significantly associated with $T_{2}$ conduct disorder diagnosis $(P=0.22)$ or conduct disorder symptoms $(P=0.08)$, binge drinking, cigarette or cannabis use $(P=0.16$ to $P=0.83)$.

Mothers' mean number of childhood ADHD symptoms was 5.13 (s.d. =4.88) and conduct disorder symptoms 2.91

Table 2 Rates of adolescent substance use and comparison data ${ }^{a}$

\begin{tabular}{|c|c|c|c|c|}
\hline & $\begin{array}{l}\text { CLASS sample } \\
\qquad(n=117)\end{array}$ & $\begin{array}{l}\text { CaStANET sample (control) } \\
\qquad(n=117)\end{array}$ & $\chi^{2}$ & $P$ \\
\hline \multicolumn{5}{|l|}{ Alcohol use, $n(\%)$} \\
\hline Ever without parents knowledge & $61(52.1)$ & $63(53.8)$ & 0.1 & 0.79 \\
\hline At least once a week & $23(19.7)$ & $13(11.1)$ & 3.3 & 0.07 \\
\hline Binge drinking ${ }^{\mathrm{b}}$ & $16(13.7)$ & $6(5.1)$ & 5.0 & 0.025 \\
\hline \multicolumn{5}{|l|}{ Cigarette use (whole cigarette), $n$ (\%) } \\
\hline Ever & $50(42.7)$ & $26(22.2)$ & 11.2 & 0.001 \\
\hline In the past 30 days & 40 (34.2) & 9 (18.4) & 24.5 & $<0.001$ \\
\hline Regularly (at least one a day) & $29(24.8)$ & $5(7.7)$ & 19.6 & $<0.001$ \\
\hline \multicolumn{5}{|l|}{ Cannabis use, $n(\%)$} \\
\hline Ever & $30(25.6)$ & $20(17.1)$ & 2.5 & 0.11 \\
\hline In the past 30 days & $19(16.2)$ & $8(6.8)$ & 5.1 & 0.024 \\
\hline Regularly (at least one a day) & $11(9.4)$ & $6(5.1)$ & 1.6 & 0.20 \\
\hline
\end{tabular}


(s.d. =3.54). Child IQ, birth weight, friendship problems, social class and maternal childhood ADHD symptoms were not significantly associated with adolescent ADHD scores or diagnosis (Table 3). However, mother's childhood conduct disorder symptoms predicted adolescent ADHD scores (Table 3 ) even when additionally controlling for the child's IQ and baseline conduct disorder symptoms $(\beta=-0.21, t=-2.18, P=0.03)$.

Children's IQ and social class, but not birth weight, friendship problems or maternal childhood ADHD symptoms, were predictive of conduct disorder outcomes. Those with a higher social class and IQ had fewer conduct disorder symptoms (Table 4), an effect strongest for performance IQ (results available from the author on request). Maternal childhood conduct disorder symptoms also significantly predicted adolescent conduct disorder symptoms (Table 4). These findings remained significant controlling for baseline ADHD and conduct disorder symptoms (full-scale IQ $\beta=-0.17, \quad t=-2.14, \quad P=0.05 ;$ social class $\beta=-0.19, \quad t=-2.21, \quad P=0.03$; maternal conduct disorder symptoms $\beta=0.20, t=2.14, P=0.04)$. These same factors also significantly predicted diagnosis of conduct disorder at followup (Table 4). All findings remained when multiple regression analysis including all significant variables concurrently was undertaken (details available from author on request).

\section{Discussion}

\section{Continued ADHD and conduct disorder}

The results of this 5-year prospective study show that despite clinical recognition, confirmation of diagnosis and freely available treatment, children with ADHD experience ongoing difficulties, particularly the persistence of ADHD symptoms and diagnoses, serious antisocial behaviour, police contact and high-risk healthrelated behaviours. Medication use for the treatment of ADHD was associated with increased ADHD severity, likely as a result of greater severity leading to continued treatment, but was not associated with other outcomes.

Even those not meeting full diagnostic criteria for ADHD at follow-up still showed substantial impairment due to their remaining ADHD symptoms. Only $10 \%$ of the sample appeared to have functionally and symptomatically recovered, some of whom continued to be prescribed medication. This is comparable with the low levels of functional remission reported in one US sample of children with $\mathrm{ADHD}^{22}$ and in UK findings that hyperactivity in childhood predicts hyperactivity in adolescence. ${ }^{23}$

There are various potential explanations why ADHD and associated impairments persisted. First, ADHD is a chronic disorder and like other chronic conditions there may simply be a high level of stability over time, with affected individuals requiring ongoing monitoring and treatment. Second, inadequate treatment may be a contributory factor. Medication is known to be initially effective ${ }^{24}$ but treatment requirements alter over time. Moreover, the treatment effect in those receiving medication through routine clinical care (compared with treatment trial medication provision) is known to be relatively poor $^{25}$ and treatment benefits appear to diminish or disappear over time. ${ }^{3}$ This could also be the case in the UK. Third, participants may not have been taking their medication. Overall, the low level of remission and high continuing impairment as a result of ADHD in this study raise concerns, suggesting that long-term approaches to the management of ADHD need review by both clinicians and researchers.

Despite recognition of ADHD by specialist services and treatment, we also found a high percentage of individuals,

Table 3 Predictors of attention-deficit hyperactivity disorder (ADHD) symptom change over time (time $2\left(T_{2}\right)-$ time $\left.1\left(T_{1}\right)\right)$ and DSM-IV ADHD diagnosis at follow-up

\begin{tabular}{|c|c|c|c|c|c|c|c|c|}
\hline & \multicolumn{4}{|c|}{ Symptom change over time } & \multicolumn{4}{|c|}{$T_{2}$ DSM-IV ADHD diagnosis } \\
\hline & $R^{2}$ & $\beta$ & $t$ & $P$ & Wald & OR & $95 \% \mathrm{Cl}$ & $P$ \\
\hline Age $\left(T_{2}\right)^{a}$ & 0.14 & 0.38 & 4.41 & $<0.001$ & 2.70 & 0.80 & $0.62-1.04$ & 0.10 \\
\hline Gender & 0.01 & 0.11 & 1.27 & 0.21 & 1.17 & 0.40 & $0.07-2.13$ & 0.28 \\
\hline Full-scale IQ & $<0.001$ & -0.01 & -0.14 & 0.89 & 1.46 & 0.98 & $0.95-1.01$ & 0.23 \\
\hline Birth weight & 0.003 & -0.06 & -0.65 & 0.52 & 1.80 & 1.00 & $1.00-1.01$ & 0.18 \\
\hline Social class & $<0.001$ & $<0.001$ & $<0.001$ & 1.00 & 1.40 & 1.39 & $0.80-2.41$ & 0.24 \\
\hline Friendship problems & 0.006 & -0.08 & -0.85 & 0.40 & 0.07 & 1.10 & $0.54-2.23$ & 0.80 \\
\hline Mother's childhood ADHD & 0.07 & -0.26 & -1.63 & 0.11 & 0.44 & 1.04 & $0.93-1.15$ & 0.51 \\
\hline Mother's childhood conduct disorder & 0.04 & -0.21 & -2.26 & 0.03 & 5.48 & 1.31 & $1.05-1.64$ & 0.02 \\
\hline
\end{tabular}

Table 4 Predictors of time 2 ( $\left.T_{2}\right)$ DSM-IV conduct disorder symptoms and diagnosis

\begin{tabular}{|c|c|c|c|c|c|c|c|c|}
\hline & \multicolumn{4}{|c|}{$T_{2}$ conduct disorder symptoms } & \multicolumn{4}{|c|}{$T_{2}$ DSM-IV conduct disorder diagnosis } \\
\hline & $R^{2}$ & $\beta$ & $t$ & $P$ & Wald & OR & $95 \% \mathrm{Cl}$ & $P$ \\
\hline Age $\left(T_{2}\right)^{a}$ & 0.002 & 0.04 & 0.48 & 0.64 & 0.21 & 1.06 & $0.82-1.37$ & 0.65 \\
\hline Gender & 0.02 & -0.13 & -1.38 & 0.17 & 0.90 & 0.35 & $0.04-3.09$ & 0.34 \\
\hline Full-scale IQ & 0.04 & -0.21 & -2.34 & 0.02 & 5.35 & 0.95 & $0.92-0.99$ & 0.02 \\
\hline Birth weight & 0.01 & -0.11 & -1.21 & 0.28 & 1.04 & 1.00 & $0.99-1.00$ & 0.31 \\
\hline Social class & 0.06 & -0.24 & -2.63 & 0.01 & 4.74 & 0.56 & $0.33-0.94$ & 0.03 \\
\hline Friendship problems & 0.005 & 0.07 & 0.75 & 0.46 & 0.10 & 1.12 & $0.57-2.17$ & 0.75 \\
\hline Mother's childhood ADHD & 0.004 & 0.07 & 0.26 & 0.72 & 0.02 & 0.99 & $0.91-1.09$ & 0.90 \\
\hline Mother's childhood conduct disorder & 0.08 & 0.29 & 2.99 & 0.004 & 3.22 & 1.12 & $0.99-1.27$ & 0.07 \\
\hline
\end{tabular}


$72.9 \%$, impaired because of antisocial behaviour and a significant increase in the diagnosis of conduct disorder at follow-up (25.5\%). A substantial number of serious antisocial acts were also committed. In UK community-based studies, $23 \%$ of adolescents (11-16 years) report ever being in trouble with the police ${ }^{26}(61 \%$ in this study) and parental report of police contact in the past year is $6.6 \%$ for adolescent males ${ }^{21}$ ( $v .21 \%$ in 3 months for this study). This suggests that individuals with ADHD represent a high-risk group for serious antisocial behaviour, with police contact, and represent a significant cost to society as well as to the individual. Thus, any long-term clinical treatment of individuals with ADHD should include monitoring and interventions for antisocial behaviour and its impact, even at diagnostic subthreshold levels.

\section{Substance use}

There is growing evidence suggesting that childhood ADHD is a risk factor or precursor for later substance use, particularly cigarette use, ${ }^{28}$ although not universally. ${ }^{29}$ In our sample, adolescents were more likely to have tried cigarettes, started smoking at a younger age and become regular smokers than a community sample. Given that drinking alcohol in early adolescence is now considered normative in the $\mathrm{UK},{ }^{30}$ it is perhaps unsurprising that there were no observed differences in the age of alcohol initiation. However, adolescents with childhood ADHD were more likely to report binge drinking ${ }^{30}$ at least once a week over the past year and are therefore at high risk of hazardous alcohol use. Adolescents with ADHD were no more likely to have ever tried cannabis but indicated more recent use, as well as starting experimenting at an earlier age (associated with greater liability for misuse and psychosis). ${ }^{31,32}$ Adolescent cigarette smoking, heavy alcohol and cannabis use have established risk effects on physical and mental health. ${ }^{33}$ Our findings suggest the need for intervention regarding these behaviours in young people with ADHD.

These findings paint a bleak picture for those diagnosed with ADHD in childhood, especially as we have also shown that a substantial proportion of these children were recognised as having special educational needs and needed additional school support. ${ }^{21}$ Future studies investigating the outcome of individuals with ADHD might wish to take into account additional outcomes such as quality of life or coping, which might provide additional information on this group.

\section{Predictors of outcome}

In line with previous studies and expectations, symptoms significantly decreased with age. We also examined child IQ and birth weight given a previous report of their importance. ${ }^{20}$ Overall, there were no strong predictors of ADHD behaviour. The exception was maternal childhood conduct disorder symptoms, although maternal ADHD symptoms in childhood were not significant. The latter lack of association might be because of the use of retrospective self-reports of ADHD, which may be less reliable than reports from informants who knew the adult as a child. ${ }^{34}$ These findings indicate that obtaining a history of the mother's own childhood conduct symptoms may be one useful marker of poorer outcome in addition to the child's own clinical presentation. ${ }^{35}$

In the MTA trial, individuals with the most consistent pattern of ADHD symptoms decline over 36 months ${ }^{20}$ had higher IQ, were heavier at birth, showed higher baseline social functioning and lower social adversity. None of these factors were associated with a decline in ADHD symptoms in our sample. However, in the MTA trial, these factors were predictive of membership of a latent class with consistent decline in symptoms, whereas other latent classes had different patterns of decline. As we did not examine latent classes within our sample, we may have missed these subtle differences. Moreover, in our UK sample, there were few individuals with higher IQ and from higher social classes.

In the MTA trial, the time between initial and follow-up assessments was fixed, whereas in this study there was variation in the length of follow-up. The MTA trial can therefore be more exact regarding the effects of time. However, in our study, time between assessments was not associated with ADHD symptom change.

It is possible that factors not investigated here may be predictive of adolescent outcome. For example, negative parenting factors influence outcomes of other disorders, but for ADHD these appear to be a consequence of the disorder. ${ }^{36}$ Research on other disorders suggests that a positive family history may also indicate those with poorer outcomes. ${ }^{37}$

In contrast to our lack of predictors for ADHD persistence, we did find predictors of adolescent conduct disorder symptoms, specifically maternal childhood conduct disorder, social class and higher IQ, the latter finding previously reported in those with and without a childhood diagnosis of ADHD. ${ }^{38,39}$

\section{Limitations}

As with nearly all longitudinal studies there was sample attrition. However, the rates of successful tracing (95\%) and engagement in the second assessment were good and there were no baseline differences between those followed up and those lost to the study. Our study design did not include any measures of individual's medication adherence, therefore we can only comment on the prescription, rather than actual taking, of stimulant medication.

We were also unable to examine paternal externalising symptoms. We had no measure of current maternal conduct disorder symptoms. However, a proxy measure of current antisocial behaviour (mother reports of being in trouble with the law in the past 5 years) was not found to be associated with child outcomes, although few mothers endorsed this item $(n=9)$.

As with any study, these finding require replication, and multiple testing could give rise to false positive results. Finally, this sample represents children with ADHD that has been recognised and diagnosed by specialist clinical services in the UK. Our findings, therefore, cannot be generalised to those in the community whose ADHD has not been identified. However, as the aims of this study were to investigate the outcomes of children with diagnosed ADHD, our findings remain clinically informative.

The results of this UK prospective study suggest adolescents who were clinically recognised, treated and met diagnostic criteria for ADHD in childhood show poor adolescent ADHD and antisocial outcomes. The findings are consistent with some US studies (e.g. Barkley et al, Biederman et al and Mannuzza et al) ${ }^{40-42}$ and demonstrate that the earlier findings generalise to another country and a different healthcare context. Even after widespread publication and dissemination of treatment guidelines, ADHD leads to a range of poor clinical outcomes. Moreover, there is a wider health risk in terms of high-risk patterns of cigarette smoking, alcohol and drug use.

There was some evidence that maternal childhood conduct disorder symptoms were associated with child ADHD and conduct disorder symptom outcomes, although the nature of this relationship requires further elucidation. However, we found no other significant predictors of ADHD continuity from baseline characteristics. This paints a bleak picture for clinicians in the field indicating that more research into other possible predictors and interventions effective in the long term is needed. However, social 
and maternal factors, as well as child IQ may be important in protecting children with ADHD from developing adolescent antisocial behaviour.

Kate Langley, PhD, Tom Fowler, PhD, Department of Psychological Medicine and Neurology, School of Medicine, Cardiff University, UK; Tamsin Ford, MRCPsych, PhD, Child Health Group, Peninsula Medical School, University of Exeter, UK; Ajay K. Thapar, MD, MRCGP, Marianne van den Bree, PhD, Department of Psychologica Medicine and Neurology, School of Medicine, Cardiff University, UK; Gordon Harold $\mathrm{PhD}$, University of Otago, Dunedin, New Zealand; Michael J. Owen, FRCPsych, FMedSci, PhD, Michael C. O'Donovan, FRCPsych, PhD, Anita Thapar, FRCPsych $\mathrm{PhD}$, Department of Psychological Medicine and Neurology, School of Medicine, Cardiff University, UK

Correspondence: Kate Langley, Department of Psychological Medicine and Neurology, School of Medicine, Cardiff University, Heath Park, Cardiff, CF14 4XN, UK. Email: langleyk@cardiff.ac.uk

First received 27 Mar 2009, final revision 22 Oct 2009, accepted 11 Nov 2009

\section{References}

1 Woodward LJ, Downey L, Taylor E. Child and family factors influencing the clinical referral of children with hyperactivity: a research note. J Child Psychol Psychiatry 1997; 38: 479-85.

2 Taylor E, Sonuga-Barke EJ. Disorders of attention and activity. In Rutter's Textbook of Child Psychiatry (5th edn) (eds M Rutter, DV Bishop, D Pine, S Scott, J Stevenson, E Taylor, et al): 521-42. Blackwell, 2008.

3 Swanson J, Arnold LE, Kraemer HC, Hechtman L, Molina BSG, Hinshaw SP et al. Evidence, interpretation, and qualification from multiple reports of longterm outcomes in the multimodal treatment study of children with ADHD (MTA). Part 1: executive summary. J Atten Disord 2008; 12: 4-14.

4 Fowler T, Langley K, Rice F, Whittinger N, Ross K, van Goozen S, et al. Psychopathy traits in adolescents with attention-deficit hyperactivity disorder. Br J Psychiatry 2009; 194: 62-7.

5 American Psychiatric Association. Diagnostic and Statistical Manual of Mental Disorders (4th edn) (DSM-IV). APA, 1994.

6 van den Bree M, Rice F, Fowler T, Shelton K, Lifford K, Scourfield J, et al. The Cardiff Study of All Wales and North West of England Twins (CaStANET) a longitudinal research programme of child and adolescent development. Twin Res Hum Genet 2007; 10: 13-23.

7 Thapar A, Harrington R, Ross $\mathrm{K}$, McGuffin P. Does the definition of ADHD affect heritability? J Am Acad Child Adolesc Psychiatry 2000; 39: 1528-36.

8 Fowler T, Lifford K, Shelton K, Rice F, Thapar A, Neale MC, et al. Exploring the relationship between genetic and environmental influences on initiation and progression of substance use. Addiction 2007; 102: 413-22.

9 Angold A, Costello EJ. The Child and Adolescent Psychiatric Assessment (CAPA). J Am Acad Child Adolesc Psychiatry 2000; 39: 39-48.

10 World Health Organization. The ICD-10 Classification of Mental and Behavioural Disorders: Clinical Descriptions and Diagnostic Guidelines. WHO, 1992.

11 Holmes J, Lawson D, Langley $\mathrm{K}$, Fitzpatrick $\mathrm{H}$, Trumper A, Pay $\mathrm{H}$, et al. The Child Attention-Deficit Hyperactivity Disorder Teacher Telephone Interview (CHATTI): reliability and validity. Br J Psychiatry 2004; 184: 74-8.

12 Angold A, Costello EJ. A test-retest reliability study of child-reported psychiatric symptoms and diagnoses using the Child and Adolescent Psychiatric Assessment (CAPA-C). Psychol Med 1995; 25: 755-62.

13 Rutter M, Giller H, Hagell A. Antisocial Behavior by Young People. Cambridge University Press, 1998.

14 Resnick MD, Bearman PS, Blum RW, Bauman KE, Harris KM, Jones J, et al. Protecting adolescents from harm. Findings from the National Longitudinal Study on Adolescent Health. JAMA 1997; 278: 823-32.

15 Weschler D. Weschler Intelligence Scale for Children (3rd edn). Psychological Corporation, 1992

16 Office for Nation Statistics. Standard Occupational Classification (2nd edn). HMSO, 1995.

17 Barkley RA, Murphy KC. Attention Deficit Hyperactivity Disorder: A Handbook for Diagnosis and Treatment. The Guildford Press, 1998.

18 Ford $\mathrm{T}$, Hamilton $\mathrm{H}$, Dosani S, Burke L, Goodman R. The children's services interview: validity and reliability. Soc Psychiatr Psychiatric Epidemiol 2007; 42: $36-49$.
19 Biederman J, Milberger S, Faraone SV, Kiely K, Guite J, Mick E, et al. Familyenvironment risk factors for attention-deficit hyperactivity disorder. A test of Rutter's indicators of adversity. Arch Gen Psychiatry 1995; 52: 464-70.

20 Swanson J, Hinshaw SP, Arnold LE, Gibbons RD, Marcus SE, Hur K, et al. Secondary evaluations of MTA 36-month outcomes: propensity score and growth mixture model analysis. J Am Acad Child Adolesc Psychiatry 2007; 46: 1003-14.

21 Ford $\mathrm{T}$, Fowler $\mathrm{T}$, Langley $\mathrm{K}$, Whittinger $\mathrm{N}$, Thapar A. Five years on: public sector service use related to mental health in young people with ADHD or hyperkinetic disorder five years after diagnosis. Child Adolesc Ment Health 2008; 13: 122-9.

22 Biederman J, Mick E, Faraone SV. Age-dependent decline of symptoms of attention deficit hyperactivity disorder: impact of remission definitionand symptom type. Am J Psychiatry 2000; 157: 816-8.

23 Taylor E, Chadwick O, Heptinstall E, Danckaerts M. Hyperactivity and conduct problems as risk factors for adolescent development. J Am Acad Child Adolesc Psychiatry 1996; 35: 1213-26.

24 National Institute for Health and Clinical Excellence. Guidance on the Use of Methylphenidate (Ritalin, Equasym) for Attention Deficit/Hyperactivity Disorder (ADHD) in Childhood. NICE, 2000.

25 MTA Cooperative Group. A 14-month randomized clinical trial of treatmen strategies for attention-deficit/hyperactivity disorder. The MTA Cooperative Group. Multimodal Treatment Study of Children with ADHD. Arch Gen Psychiatry 1999; 56: 1073-86.

26 Ford T, Goodman R, Meltzer H. The British Child and Adolescent Mental Health Survey 1999: the prevalence of DSM-IV disorders. J Am Acad Child Adolesc Psychiatry 2003; 42: 1203-11.

27 Molina BSG, Pelham WE. Childhood predictors of adolescent substance use in a longitudinal study of children with ADHD. J Abnorm Psychol 2003; 112 497-507.

28 Young S, Heptinstall E, Sonuga-Barke EJ, Chadwick O, Taylor E. The adolescent outcome of hyperactive girls: self-report of psychosocial status. I Child Psychol Psychiatry 2005; 46: 255-62.

29 British Medical Assocaiton. Adolescent Health. BMA Publishing Unit, 2003.

30 Glantz M, Pickens R. Vulnerability to Drug Abuse. American Psychological Association, 1992

31 Arseneault L, Cannon M, Poulton R, Murray R, Caspi A, Moffitt TE. Cannabis use in adolescence and risk for adult psychosis: Iongitudinal prospective study. BMJ 2002; 325: 1212-3.

32 Saraceno L, Munafo M, Heron J, Craddock N, van den Bree MBM. Genetic and non-genetic influences on the development of co-occurring alcohol problem use and internalizing symptomatology in adolescence: a review. Addiction 2009; 104: 1100-21.

33 Jensen PS, Rubio-Stipec M, Canino G, Bird HR, Dulcan MK, Schwab-Stone ME, et al. Parent and child contributions to diagnosis of mental disorder: are both informants always necessary? J Am Acad Child Adolesc Psychiatry 1999; 38: 1569-79.

34 Whittinger N, Langley K, Fowler T, Thomas H, Thapar A. Clinical precursors of adolescent conduct disorder in children with attention-deficit hyperactivity disorder. J Am Acad Child Adolesc Psychiatry 2007; 46: 179-87.

35 Lifford KJ, Harold GT, Thapar A. Parent-child relationships and ADHD symptoms: a longitudinal analysis. J Abnorm Child Psychol 2008; 36: 285-96.

36 Milne BJ, Caspi A, Harrington H, Poulton R, Rutter M, Moffitt TE. Predictive value of family history on severity of illness: the case for depression, anxiety, alcohol dependence, and drug dependence. Arch Gen Psychiatry 2009; 66: 738-47.

37 West D, Farrington D. Who Becomes Delinquent? Heinemann, 1973.

38 Simonoff E, Elander J, Holmshaw J, Pickles A, Murray R, Rutter M Predictors of antisocial personality. Continuities from childhood to adult life. Br J Psychiatry 2004; 184: 118-27.

39 Barkley R, Fischer M, Smallish L, Fletcher K. Young adult outcome of hyperactive children: adaptive functioning in major life events. J Am Acad Child Adolesc Psychiatry 2006; 45: 167-79.

40 Biederman J, Monuteaux MC, Mick E, Spencer T, Wilens TE, Silva J, et al Young adult outcome of attention deficit hyperactivity disorder: a controlled 10-year follow-up study. Psychol Med 2006; 36: 167-79.

41 Mannuzza S, Klein RG, Moulton 3rd JL. Persistence of attention-deficit/ hyperactivity disorder into adulthood: what have we learned from the prospective follow-up studies? J Atten Disord 2003; 7: 93-100. 